\title{
The next Silicon Valley? On the relationship between geographical clustering and public policy
}

\author{
Gert-Jan Hospers • Pierre Desrochers • \\ Frédéric Sautet
}

Published online: 5 March 2008

(C) The Author(s) 2008

\begin{abstract}
Inspired by the success of geographical clustering in California, many governments pursue cluster policy in the hope to build the next Silicon Valley. In this paper we critically assess the relationship between geographical clustering and public policy. With the help of a range of theoretical insights and case study examples we show that cluster policy in fact is a risky $\backslash$ venture, especially when it is tried to copy the success of regional 'best practices'. Therefore, we advice policy makers to move away from the Silicon Valley model and to modestly start from a place-specific approach of 'Regional Realism'.
\end{abstract}

Keywords Clustering - Geography - Innovation · Public policy · Austrian economics

\section{Introduction}

All over the world, public authorities are trying to build the next Silicon Valley. At the moment, Silicon Valley, the nickname of Santa Clara and neighbouring counties in California, is possibly the world's most famous example of the geographical clustering of economic activity (Saxenian 1994; O'Mara 2004). For long, Santa Clara County and its main cities, San Jose and Palo Alto, were mostly known for their orchards. In 1891, however, Leland Stanford, a former California Governor and railroad magnate, founded Stanford University. Under the leadership of Frederick Terman (1900-1982), the institution became a prominent engineering school and a breeding place for new, innovative companies. One of these spin-offs was established in 1939 by Stanford classmates Bill Hewlett and Dave Packard, who

\footnotetext{
G.-J. Hospers $(\bowtie)$

School of Business, Public Administration and Technology, University of Twente, P.O. Box 217, 7500 AE Enschede, The Netherlands

e-mail: g.j.hospers@utwente.nl

P. Desrochers

Department of Geography, University of Toronto at Mississauga, Mississauga, Canada

F. Sautet

Mercatus Center, George Mason University, Arlington, VA, USA
} 
developed numerous electronic devices. Ever since, the micro-electronics cluster of Silicon Valley has developed semiconductors and computer chips that are sold world-wide to component and system manufacturers.

Dazzled by this success story of clustering, many officials have paid a 'policy visit' to the area over the years. One of these first 'policy tourists' was the Russian leader Khrushchev who was so impressed by what he saw that he led an attempt to replicate it in Akademgorodok in the middle of Siberia. The planned 'City of Science', however, failed to produce the Silicon Valley effect the Russian president had hoped for (Josephson 1997). Krushschev's attempts, however, was but one of several 'Silicon Somewheres' and 'Tech Valleys'; that would be launched the world over in later years as other political leaders, from Charles de Gaulle to local mayors, tried to emulate the Northern California success story (Bouwman and Hulsink 2000; O’Mara 2004; Stuart and Kargon 1996). In recent times, spontaneous cluster formation and regional high-tech clustering policy initiatives have included Silicon Alley (Manhattan-New York), Silicon Snowbank (Minneapolis-St.Paul-Area), Silicon Desert (Phoenix), Silicon Mountain (Colorado Springs), Silicon Prairie (Champaign-Urbana), Silicon Dominion (Virginia), Silicon Hills (Austin), Silicon Forest (Seattle), Silicon Fen (Cambridge), Silicon Glen (Glasgow), Silicon Bog (Limerick), Medicon Valley (Copenhagen), Silicon Seaside (South-Norway), Silicon Saxony (Sachsen), Bavaria Valley (Bayern), Silicon Polder (the Netherlands), Dommel Valley (Eindhoven), Silicon Kashba (Istanbul), Shalom Valley (Israel), Silicon Plateau (Bangalore-India), Media Valley (Inchon-South Korea), BilliCan Valley (Arnhel Land-Australia) and Telecom Valley (Minas Gerais-Brazil).

Against this background, this article examines the link between successful geoeconomic clustering on the one hand and cluster policy on the other. It asks whether there is a role for government in facilitating cluster formation and support and whether there is a difference here between high-tech and low-tech clusters. In other words, is it possible to build the next Silicon Valley with the help of public policy or should policy makers stick to 'old economy'-clustering? In exploring these issues we make use of theoretical insights and anecdotal evidence regarding clusters and cluster policy. The article is structured as follows. After a critique on the concept of clusters, we argue that, despite claims to the contrary, cluster policy remains a form of industrial policy that implies a form of targeting. We then discuss the general pitfalls of cluster policy as well as the risks associated with policy towards high-tech and low-tech clusters. Given the fact that governments always want to facilitate clustering anyway, we present case examples of successful clusters in which government played no or only a limited role, e.g. in the field of cluster marketing. Without exception, these examples show how important it is to take into account the particularities and realities of an area. The article concludes by suggesting that policy makers should move away from strategy aimed at trendy 'Silicon Somewheres' towards a no-nonsense approach of 'Regional Realism'.

\section{Geographical clustering and public policy: general criticism}

Harvard University Professor Michael Porter (2000a, p. 254), one of the leading advocates of cluster policy, defines a cluster as “... a geographically proximate group 
of interconnected companies and associated institutions in a particular field, linked by commonalities and complementarities". Clusters are thus made up of various parties, ranging from specialized suppliers, service providers and firms in related industries, to universities, standards agencies and trade associations, while their geographical concentration is said to facilitate the movement of ideas and people between them, in the process promoting and reinforcing innovative behavior.

\section{Clusters: a fuzzy concept}

In spite of a neat definition, it is difficult to trace and fix clusters in practice as all industries ultimately depend on each other. As a matter of fact, a cluster is often in the eye of the policy maker or adviser. For example, in Porter's framework the geographic scope of a cluster can range from a region, a state, or even a single city to span nearby or neighboring countries. The elasticity of the concept therefore makes it difficult to determine where a cluster begins or ends. As the cluster guru Porter puts it: "The geographic scope of a cluster relates to the distance over which informational, transactional, incentive, and other efficiencies occur... Drawing cluster boundaries is often a matter of degree and involves a creative process informed by understanding the linkages and complementarities across industries and institutions that are most important to competition in a particular field" (Porter 2000b, pp. 16-17). According to Porter, the United States disposes of 60 clusters, whereas the OECD has identified more than 300 of them (Martin and Sunley 2003). At one extreme, the term refers to national groups of industries and firms that are strongly linked, but dispersed over several different locations within a country. At the other, clusters are identified as local groupings of similar firms in related industries within a highly spatially circumscribed area. In between, clusters have come to encompass even such entities as the K-12 Minnesota public school system (Rosenfeld 2001).

Martin and Sunley (2003) point out that the main explanation for this conceptual confusion is that clusters are constructs with essentially no self-defining boundaries, whether in terms of inter-sectoral, inter-firm linkages, information networks and geographical reach. Because of their elusive character, clusters are ideally suited for various political agendas. As Norton (1999, non-paginated) puts it: "To skeptics, cluster theory sometimes looks like a vehicle for state and local government officials in search of a targeting rationale." Martin and Sunley (2003) further add to that most cluster policies do not identify working clusters, but rely instead on more immediately and statistically visible industrial sectors, which rarely conform to clusters. In practical terms, policy makers are typically under pressure to find clusters in as many areas - be it countries, regions or cities - as possible for fear of offending some of their voters' interests. While in theory Porter's clusters are not necessarily economically highly specialized entities (industries), in reality virtually all identified clusters are defined in such a narrow way.

Practical considerations also explain the inherent 'fuzziness' of cluster boundaries. While concentrations of economic activity mostly result from spontaneous results of market processes, the different capital requirements of various industries have resulted in widely different geographical scales, ranging from the regional to the street level. Furthermore, cities have their basis in a unique human trait, the propensity, as Adam Smith (1776 [1976], p. 25) famously wrote, to "truck, barter 
and exchange one thing for another" which in turn leads to an ever increasing and geographically dispersed division of labour. As a consequence of this human propensity to exchange, cities have never been predominantly closed or selfsufficient systems, but rather nodal points of trade where individuals belonging to various firms and networks interact on different geographical scales. The result is that even in highly advanced cluster-based economies such as Silicon Valley, outside buyers and suppliers are typically deemed more important by local firms than their surrounding neighbors (Desrochers 2000).

Finally, the identification of clusters is hampered by the lack of trustworthy statistical material in this field. Because of limited data availability, clusters are often reduced to industries that can be traced to national industrial classification systems. In practice, however, clusters rarely conform to sectors. If, instead, parts of a cluster are put under different traditional industrial or service categories, the problem arises that significant clusters might be obscured or unrecognized. On top of this, industrial classification schemes are themselves highly problematic. Indeed, as the economic Zvi Griliches (1990) once noted, economic 'sectors' as defined by government statisticians may be nothing more than a 'mirage'. Among other problems is the fact that industrial classifications hide the multi-product nature of many firms and the very different expertise of their employees. Furthermore, even standard industry boundaries are typically arbitrary. For example, the old American Standard Industrial Classification System used both 'product' and 'production process' criteria to delineate various categories, while ignoring important industries like plastics and electronics as distinct categories (Desrochers 2001).

The need to target in cluster policy

Cluster policy refers to all those efforts of government to develop and support clusters in a particular area. It is often regarded as more modest in its ambitions than traditional industrial policy which was aimed "at particular industries (and the firms as their components) to achieve the outcomes that are perceived by the state to be efficient for the economy as a whole" (Chang 1994, p. 60). The instruments that are used to influence an industry's behavior include import tariffs, subsidies to declining or emerging sectors as well as public schemes promoting $\mathrm{R}$ and D-investments. Porter (2000a, p. 27) argues that "the intellectual foundations of cluster theory and industrial policy are fundamentally different, as are their implications for government policy". To him, cluster policy is more general in focus and support mechanisms than traditional industrial policy. In essence, Porter (2000a) sees his approach as a framework geared towards the 'competitiveness' of a given country or region. His reasoning is that areas with industries that are embedded in wide and deep clusters are more competitive than other places. The concept of 'competitiveness' refers to the quality of an area's business environment and as such to framework conditions, like the availability of natural resources, skilled labour and especially the presence of strong clusters. In this respect, cluster policy should be aimed at "removing obstacles, relaxing constraints, and eliminating inefficiencies that impede productivity and innovation in the cluster" (Porter 2000a, p. 26). 
Ideally, governments pursuing cluster policy should shift their attention from targeting and subsidizing particular industries towards facilitating the development and functioning of clusters in the economy. In the literature, this desired change in policy orientation has been described as a move away from specific to generic policy, a transition from direct to indirect intervention and a shift from vertical to horizontal policy (see e.g. Chang 1994 and McDonald and Dearden 2005). Cluster policy can be seen as part of a new 'heterodox' economic policy framework in which significant dimensions of economic policy at large are being reformulated in terms of area-based framework policy (Storper and Scott 1995). In practice, however, cluster policy is hard to isolate from other economic policy approaches. Meanwhile, cluster-based initiatives can be found under several headings in policy documents and statistics, such as industrial policy, innovation policy and regional development policy. At Ministries of Economic Affairs, for example, departments that were in charge for industrial policy mostly have become responsible for cluster policy, while regional development agencies have transformed regional network programmes into cluster initiatives (Rosenfeld 2001).

At first sight, framework policy supporting clusters for competitiveness seems to be indeed more generic and market-friendly than more interventionistic past approaches such as state aid to 'national champions' or 'picking the winner' strategies (Chang 1994). Upon reflection, however, cluster policy implies a form of targeting as well. Firstly, there is a great deal of selectivity ingrained in the concept of 'competitiveness' (Reinert 1995). To raise an area's competitive advantage vis-àvis other areas, government officials still have to decide which economic activities should be supported and which ones should be left to face market forces. Secondly, even if the goals of cluster policy are generic, the tools used to achieve these goals often implicitly favour certain activities. Public investments in an area's science base or R and D-subsidies simply cannot benefit all clusters, but will always be biased towards particular parts of the economy (Cowling et al. 1999). For example, a biotechnology cluster is more likely to make use of innovation-oriented policy schemes than a cluster of the 'old' economy (e.g. coal production) where opportunities for radical renewal are less obvious. Public authorities can therefore not escape from targeting strategies, whether they operate in a cluster-based framework or not.

All in all, Porter's attempt to differentiate cluster policy from industrial policy is not convincing. Because cluster theory and industrial policy have similar problems of selection and implementation, it is hard to maintain that the two policy philosophies are fundamentally different. Porter seems to have made a fine distinction, but in practice cluster strategy does amount to picking winners or backing losers (Norton 1999, non-paginated) and does constitute a radical break from past practices. Indeed policy makers are making clear choices when devising cluster policy: they pursue either an offensive type of policy aimed at stimulating high-technology clusters (e.g. information-, bio-and nanotechnology) or a defensive type of cluster policy addressed at preserving traditional activities (for example, textiles, automotive and machinery). In short, their goal is the development of either a Silicon Somewhere or a Rising Rustbelt (Hospers 2004a). We will see that such targeting has a long and unsuccessful history. Therefore, policy makers in charge for cluster policy should take care not to make the same mistakes as before. 


\section{The pitfalls of public policy towards geographical clustering}

In practice, clusters are often reduced to industries and treated as such by policymakers. Moreover, we saw that cluster policy is about targeting and therefore involves issues reminiscent of industrial policy. This section dwells on the pitfalls of cluster policy. To start, we focus on the general difficulties regarding public targeting. Thereafter we have a look at the special problems that emerge in targeting high-tech clusters on the one hand and low-tech clusters on the other.

\section{Targeting and information asymmetries}

Given the fact that government cannot support every cluster in a similar manner, it has to choose which clusters get special attention and which not. In grounding the choice for particular clusters, policy makers mostly make use of economic-scientific arguments. These arguments, however, may be criticized; often they are not scientific at all, but rather political, while ignoring economic warnings and historical evidence against targeting. With regard to the alleged academic grounding of cluster policy Buss (1999, p. 343) argues that typically "targeted industry studies use poor or inappropriate data, deeply flawed social science methods, and simplistic mathematical models in producing targets. Targets themselves tend to be dubious". As Buss sees it, targeting strategies, including cluster-based targeting, are not practiced because of their scientific merit, but because of their appeal to certain political constituencies. Impressive analytics (e.g. cluster studies carried out by Porter and his team) can be produced on demand to justify inherently political proposals and - as they have the appearance of scientific backing - quickly generate a 'herd effect' among policy advisers. Once policy makers in some regions or localities develop targeting strategies, others feel compelled to follow suit.

The economist Joseph Schumpeter emphasized early on the intimate relationship between politics and policy. "Nobody has attained political maturity who does not understand that policy is politics. Economists are particularly apt to overlook these truths" (Schumpeter 1950, p. 8). In addition to Schumpeter's cynical view, there are also sound economic-scientific reasons that teach us that policy-makers are not in a better position than market actors for 'cluster picking'. As public choice theory makes clear, 'government failure' is as common as 'market failure' owing to massive information asymmetries and strategic behavior by politicians and bureaucrats (Wolf 1990). Among other problems, governments officials typically have little understanding of the dynamics of business life and are too removed from the workplace to identify real opportunity areas. After all, there is a inherent and fundamental difference between the public sphere (politics) and private sphere (commerce). Since both arenas have their own moral foundations and constitute different 'systems of survival', interference by one in the other system generally should be avoided as much as possible (Jacobs 1992).

Especially in issues around clustering large information asymmetries between entrepreneurs and policy makers are likely to occur. This has to do with the 'tacit' character of spatial clustering. As a matter of fact, geographical agglomeration is closely related to the generation and transmission of tacit knowledge based in "particular circumstances of time and place" (Hayek 1948). In a cluster, the crucial 
knowledge is not so much knowledge that is explicit, formalized and easily to communicate, but rather non-standardized knowledge that is embodied in human capital and acquired through experience. This knowledge can hardly be specified; in essence, it can only be bought and sold through the transfer of individuals. It is the sum of experience that firms in a cluster buy when they hire individuals who have 'been around' for a long time. It is knowledge that only individuals who have been working in the same industry or firm for a certain amount of time possess. This 'tacit' character of clustering helps to explain the particular 'industrial atmosphere' that Marshall (1890 [1947], p. 225) already noticed in success stories of clustering of his time, like the 'industrial district' around Sheffield. In such places, Marshall notes, one can feel something 'in the air' producing the effect hat "if one man starts a new idea, it is taken up by others and combined with suggestions of their own; and thus it becomes the source of further new ideas".

In this respect, MacDonald (1992) argues that government officials are not well placed to deal with the flows of tacit knowledge that make the richness of prosperous clusters. They miss the know-how, know-who and experience of the participants in the clusters they address. One cannot predict in advance which policy measures will be needed in cluster, as the activities in a cluster that demand certain support cannot be determined beforehand; these demands depend on the particular circumstances of time and place. Moreover, in most cases, policy won't even touch the knowledge about the reality of the current marketplace, as well as knowledge about a potential future state of the market. As illustrated by the genesis of the micro-electronics cluster in Silicon Valley, the birth, life and death of clusters is essentially part of a spontaneous order that rests on entrepreneurial discovery and the generation of explicit and tacit knowledge. To be sure, clusters are important to economic performance. However, officials should realize that they often will form spontaneously and that the role of (local) tacit knowledge in their development is fundamental. Predicting which activities are going to produce clusters the future is not possible. In the end, clustering is the result of entrepreneurial activity and is driven by the production of goods and services to seize profits. Government cannot simply supersede the market in the creation of those clusters (Sautet 2002b).

Picking winners: trendy high-tech clusters

Inspired by the Silicon Valley-phenomenon most governments tend to focus on hightech clusters in their attempts to raise competitiveness. In general, high-tech activities like information and communication technology (ICT), biotechnology and nanotechnology is considered to be exciting and modern and therefore worth to stimulate (Drucker 1985). High-tech cluster policy, however, involves at least three dangers.

First, as we discussed in detail above, there are no fundamental reasons to believe why policy makers are better informed than entrepreneurs in assessing the future economic potential of particular ventures (including clusters). Due to the inherent uncertain character of new technologies such government failure is likely to occur especially when it comes to high-tech clustering. As Schmookler (1966, p. 199) argues, almost all instances of innovative activities that he studied were not stimulated by policy-pushed scientific research but by the realization that a costly 
problem had to be solved or that a profit opportunity could be seized. According to Miller and Côté (1985), this is one of the main reasons why 'innovation centers' and other greenhouses in innovation parks opened in the USA and Canada in the 1970s and 1980s have failed without exception. Also French high-tech policy in the 1980s shows the risks of a strategy of picking winners. After five years of subsidizing the micro-electronics sector the French had to admit that they backed the wrong horse. One of the reasons why French high-tech policy failed was the lack of commercial insight among the public elites whose only aim was to make France world-leading in micro-electronics. For a more recent case of public ignorance on technological development, think of the world-wide hype around information technology: to be sure, the impact of this technology is important, but it certainly has not led to the 'new economy' the authorities hoped for (Clarke 2001).

Further, the possibility for areas to reap profits from high-tech clusters may be limited - and not only because high-tech normally offers far less employment than low-tech or no-tech sectors (Drucker 1985). More important than this job-argument is the fact that in the global innovation race most areas target similar activities. Usually, public authorities want to run each other close, the consequence being that nearly all of them support the development of information-, bio- and nanotechnology clusters. All over Europe it is tried to create 'Silicon Somewheres' now (see the introduction for a list of examples). As suggested in the literature on industrial organization, however, real competitive advantage does come from making a difference, not from copying rivals (Martin 2001). By mirroring themselves with Silicon Valley, areas do not make clear how they differ from one another; in fact, they only strengthen the 'first mover advantage' of the Californian high-tech hub. Apart from that, from a supranational (e.g. European or North-American) perspective the current bandwagon effect in high-tech cluster policy fosters excessive investment (duplication) in the same technologies. This herd behaviour may lead to overcapacity, bubbles and ultimately a crash in which only the fittest actors survive (Lux 1995). Likewise, by investing in similar technologies and copying 'best practices', areas undermine their potential competitive advantage and should not be surprised that in the end a painful shake-out will occur.

Finally, in supporting high-tech clusters authorities often ignore the question whether the preconditions for such clusters are present in an area. Differences in starting-position, economic structure and institutional particularities are important. Evolutionary economists have shown that innovation often derives from chance events or a unique socio-economic setting (Witt 1993). Thus, what works in one area is not necessarily suitable or feasible for another territory. A location, for example, is unlikely to be successful in high-tech clustering without having enough 'absorptive capacity' for new technologies (Cooke 2002). If a place lacks such a 'receiving system', cluster policy may be risky. Castells and Hall (1994) provide compelling evidence that the costs of starting clusters from scratch are very high and that it may take at best a long time before clusters are embedded. An example of policy failure in high-tech clustering is Akademgorodok in Russia. After the model of Silicon Valley this Siberian 'city of science' was built 'ex nihilo' in the 1950s. Since then, the place has been languishing for decades. Other cases pointing to the importance of embeddedness in clustering come from Southern-Italy and the Ruhr Area (Hospers 2004a). Here, ambitious policy initiatives in the 1960s and 1970s were 
simply rejected by the environment. Both the industrial complexes in Sardinia and the high-tech sectors in the Ruhr Area turned out to be disembodied and ended as 'cathedrals in the desert'.

\section{Backing losers: traditional low-tech clusters}

It is not only high-tech activities that policy makers support in their cluster policies. Many states and localities are stuck with the heritage of the 'old economy' of a lowtech or no-tech character (Hayter 1997). Due to fierce competition and declining demand notably old industrial areas specialized in textiles, coal and steel making, ship building, food processing and car production have come into difficulties. Although these 'national champions' often have undergone a restructuring process over the last decades, most of them still obtain aid under the heading of cluster or regional policy (Tödtling and Trippl 2004). Is such a low-tech cluster policy a viable alternative to the current trend among policy makers to build their own 'Silicon Somewheres'?

In contrast to many high-tech activities these clusters are at least embedded in their environment and usually employ a large number of people (Fingleton 1999). In terms of the popular field of 'new economic geography', one might say that the increasing returns to scale in these traditional industrial activities have laid the foundation for long-term comparative advantage (Puga 2002). Thus, these clusters have had the chance to prove their viability for the economy. Examples are coal and steel in Wallonia (Belgium), forestry in Scandinavia and Canada, automotive in SouthernGermany, watch making in the Arc Jurassien (Switzerland), textiles in Northern-Italy, snowclearing equipment in Finland, irrigation machinery in Israel and wine making in California. However, the way in which officials mostly support such clusters is subject to criticism. In fact, the authorities run the risk of 'backing losers'.

For one thing, public policies aimed at low-tech clusters frequently pursue a divergent mixture of goals, which immediately precludes an optimal policy response. Political desires to keep 'national champions' alive are often hazily mixed with objectives of restructuring, employment issues and national industrial policy considerations. Authors working in 'policy studies' continue to emphasize that having such multiple objectives for one policy are highly dangerous, as they may conflict and thus rule out the possibility for a clear-cut strategy (Dunn 2003). In fact, we are dealing here with Tinbergen's famous principle of the 'equality of instruments and targets': it is impossible to reach different economic goals (e.g. full employment and sustainable economic growth) with one general instrument. Instead, the attainment of every objective requires the use of a specific instrument (Tinbergen 1952). Dutch policy towards shipbuilding from the 1970s until today is a dramatic case in which this principle has been overlooked. Time after time sound economic reasons to shrink Dutch shipyards have been overridden by short-term employment thinking, a desire to continue the Dutch maritime pride and employment aims, e.g. in the north of the Netherlands (Groningen, Friesland). Since the 1970s, English policy makers have made similar mistakes in automotive manufacturing. The simultaneous pursuing of social, restructuring, nationalistic and economic goals did not work and may explain the decline of car production in the UK - varying from the bankruptcy of British Leyland in the past to the case of Rover recently. 
For another thing, the set-up of most low-tech cluster policies does not cure the underlying problems of the activities targeted. These programmes often consist of subsidy schemes for industrial firms that have come into financial difficulties. In theory, old industrial clusters may be supported temporarily to be able to revitalise (Tödtling and Trippl 2004). The problem is that starting subsidies is easier than stopping them. Even worse, there is a possibility of 'subsidy addiction' in that areas become fully dependent on public support (Howitt 1996). After all, subsidy-based policy measures in traditional sectors often do not help firms to restructure, but instead contribute to the maintenance of inefficiencies accumulated in the past. The institutional school in economic geography argues that especially old industrial regions are likely to fall in this inefficient subsidy-trap (Fuchs and Shapira 2005). That has to do with the phenomenon of 'lock-in' and the 'not-invented-here syndrome', i.e. the tendency of formerly successful areas to stick to existing patterns rather than to pace up with changing economic circumstances. Typical cases are Wallonia and the Ruhr Area since the 1960s. For a long time, close local networks of industrialists and politicians maintained the employment in coal and steel artificially and thus delayed the reorientation of the region into new activities. In short, low-tech cluster policy may frustrate the restructuring process needed for adjusting production to consumer's demand. Consequently, the connection of the region with new market developments may be missed.

\section{If you can't help, please do not harm}

So far, we have criticized cluster policy by arguing that in fact it amounts to industrial policy with the associated risks. But while one may acknowledge that governments are limited in their capacity to establish a successful industrial policy, one may still see a role for governments, which is to facilitate cluster emergence as opposed to design it. The issue of facilitation is not new in policy, but it has gained more prominence in recent times, especially in Anglosaxon countries. Industry New Zealand, the UK Department of Trade and Industry and Industry Canada, for example, see the facilitation of clusters as a core governmental role that is akin to, say, infrastructure development. Is this a suitable method to avoid the risks of picking winners and backing losers?

In practice, government facilitation of clusters may have the same effect as more interventionist types of cluster policy. After all, similar problems regarding knowledge and incentives may emerge. The Austrian economist Kirzner has often stressed the idea that the main peril of public policy (in his terminology: regulation) is the stifling of the entrepreneurial discovery process. He sees four main reasons why this is the case (Kirzner 1979):

1. Regulator's ignorance of the counter factual,

2. The impossibility for regulators to discover opportunities for coordination improvements in the absence of a profit motive,

3. The potentially stifling impact of regulation on the discovery process and

4. The likelihood that regulation may propel the market in a direction which is not desired by consumers (Kirzner 1979; Sautet 2002a). 
By stifling the entrepreneurial process, regulation reduces the capacity of the market to generate knowledge that could otherwise improve the coordination of individuals' plans. In other words, the fundamental problem of market-oriented public policies (including market facilitation) is that it reduces the coordinative properties of the market system.

As we stressed before, policies that promote clustering often amount to picking winners or backing losers. This is because governments cannot generate the knowledge that would be required to make most clusters work. There is no reason to think that under the institutional arrangements where governments take an active role in cluster promotion, the relevant knowledge will be generated. Thus, even if governments were composed of individuals who had only the public welfare in mind, they would still not be able to implement successful cluster policies. The limits of governmental active policies are not so much in the nature of men, but in the knowledge that is required to implement these policies (Sautet 2002b). Seen from this perspective, government facilitation of clustering is just a variation on the theme of industrial policy. It is a way of promoting government intervention, while feigning to be non-interventionist. This is because facilitation policy may have the form of, again, a subsidy scheme that is inherently biased and moreover is not required. After all, if it facilitates clusters that would have succeeded anyway, it is not needed. Alternatively, if it facilitates firms that would have otherwise failed, it interferes with the selective process of the market - thus subsidizing what would not have come into existence in the first place.

Government facilitation of clusters may fall into the traps associated with picking winners or backing losers. At any given time in any place, there is a limited amount of resources available. Therefore, agencies that do the facilitating still have to select which clusters are being helped and which not. Since there is no reason to think, as Kirzner (1979) argues, that governments face the incentives and possess the knowledge that would help them succeed in their selection process, facilitation does not differ from any other type of cluster policy. It is only through the trial and error process of the market that the best industrial structure emerges at one given point in time and space. Fundamentally governments should make sure not to interfere with the coordinative properties of the market and not to limit the ways in which change is taking place. The life and death of cities, industries and regions is inevitable in a 'living economy' (to use Mises's words), governments should not slow this process down. This fact of life is a warning for policy makers in general and cluster policy officials in particular. Or, to put it in the famous words of Hippocrates (Epidemia I): "If you can't help, please do not harm" (cited in Salacuse, 1994).

\section{What role, if any, for government?}

If both interventionist and facilitation cluster policy are risky, is there any role left then for cluster policy? To answer this question, we take a quick look at the emergence of some examples of successful clustering and the way government has contributed to that success. Table 1 lists a few 'success stories' from Europe (see Hospers $2004 \mathrm{~b}$ for more illustrations). As the table shows, in some places traditional industrial crafts have been rejuvenated by fostering the introduction of high- 
Table 1 European examples of successful clustering by combining trends and traditions

\begin{tabular}{llll}
\hline European region & Local tradition & Global trend & New combination \\
\hline Arc Jurassien & Watch making & Marketing and lifestyle & Swatch watches \\
Emilia-Romagna & Textiles industry & High-tech production & Trendy fashion \\
Baden-Württemberg & Machine tools & Growing digitalisation & Multimedia devices \\
Jutland & Furniture & Quality and lifestyle & Design furniture \\
Manchester & Heavy industries & Pop music/pop art & Cultural industries \\
North-Pas-de-Calais & Clothing sector & Need for convenience & Mail order services \\
Ruhr Area & Heavy industries & Experience economy & Industrial culture \\
Dunakanyar & Bathing culture & Ageing and wellness & Health resorts \\
Krakow Region & Building and painting & Need for maintenance & Restoration services \\
\hline
\end{tabular}

technology in design, production and marketing. With such a strategy 'new combinations' have been realised in Swiss watch making, Italian textiles and Danish furniture. Other cases show how the expertise of a declining sector may be exploited for emerging trends. The pop music and art cluster in Manchester (UK) and the multimedia cluster in Baden-Württemberg (Germany) can be traced back to the prior existence of industries whose know-how on advanced materials proved to be useful for the new businesses. Other areas have taken advantage of the trend that demand for consumer services is rising. In North-Pas-de-Calais (France) several textile factories have been transformed into mail order firms specialized in clothing, while in the Ruhr Area (Germany) former mines and steel factories are used for touristic purposes ('industrial culture'). Relevant examples of such 'trend through tradition' in Central and Eastern Europe are modern health resorts around Hungarian spas and high-tech restoration services in the Polish building cluster.

In an attempt to explain the strong performance of these clusters, three points stand out. In the first place, the examples suggest that successful clusters almost always have their basis present economic structure. The centuries-old tradition of watchmaking in Switzerland, coal and steel in the Ruhr Area and spas in Hungaria, to highlight just a few examples, have laid the fundamentals for modern clusters in these areas. Apparently, where areas are going to, still depends upon where they are coming from (Hassink 1997). Even if it may be a trivial statement, the economic perspectives of an area cannot be but somehow connected to its past. Thus, these examples are not 'best practices' but rather 'unique practices', demonstrating only that it is always an area's uniqueness that counts for regional competitiveness. In the second place, unlike an approach of 'backing losers', building on the past only makes sense when a cluster's traditions are connected to global trends. In fact, successful clusters are always - to paraphrase Schumpeter's (1912) term for innovations - 'new combinations' of local traditions and global trends. As the table shows, such global-local interfaces with opportunities for growth may come from joining existing economic activities in an area, upgrading traditional industries for the new economy or making use of old industrial knowledges for novel purposes as dictated by economy-wide, structural developments. In the third place, it is striking to see how little government has contributed to the success of the clusters. All of the clusters have emerged spontaneously, and when government did play a role in a cluster, it was only in the period after its emergence. 
Let us take a look at the government role in the clusters reviewed in the table (Hospers 2004b). In some areas public authorities have been largely absent in the clustering process. This was the case in Manchester, North-Pas-de-Calais, Dunakanyar and the Krakow Region. To be sure, the governments of these regions brand their areas now for touristic and business purposes by highlighting their strong regional clusters-but only after the clusters emerged spontaneously. In EmiliaRomagna, Baden-Württemberg and Jutland and the government has enabled the creation of business support and technology transfer centres providing 'real services' (e.g. technological advice and networking events) to the clusters. The government did not interfere in the cluster, but only offered information and contacts on demand of the business community. Admittedly, this may be seen as a type of 'facilitation policy', but because of its concrete, non-interventionistic and ex-post character public involvement in fact has been harmless. In other places government has entered the scene predominantly in the marketing of the cluster. In the Jura d'Arc, Baden-Württemberg and the Ruhr Area, it was the local business community that decided to join forces and develop clusters in the field of watchmaking (Swatch), industrial culture respectively multimedia technology. When the resulting clusters turned out to be a success, the government joined in and took care of the marketing (branding) of the clustering in the outside world. Thus, the regions have been promoted as 'places to be' for parties (investors, tourists) interested in the activities of the clusters. This public 'cluster marketing' does not really harm the market process as long as its aim is to attract the attention of new investors or clients contributing to the continuation of its performance (Kotler et al. 1993; Rainisto 2003). The motto 'be good and tell it' also applies to clusters: cluster parties themselves should take care for being good, while government may advertize the success of clusters that have passed the market-test.

\section{Conclusion: towards an approach of 'regional realism'}

Inspired by the clustering success of Silicon Valley, many governments pursue cluster policy in the hope to build their own 'Silicon Somewheres'. Cluster policy is widely regarded as a strategy that is less pretentious than traditional, more selective economic policies. If we may believe Porter (2000a), cluster policy is-unlike industrial policy - a horizontal and market-friendly approach. In this article we have criticized this view on several grounds. For a start, due to the fuzziness of the cluster concept clusters are often reduced to industries and treated as such by public authorities. Furthermore, cluster policy is (like traditional industrial policy) a matter of targeting: policy makers have to decide which clusters to help and which not. In general, this is a risky venture because of large information asymmetries between entrepreneurs and policy makers. Particular problems emerge when it comes to hightech cluster policy and low-tech cluster policy. The first strategy resembles an industrial policy of 'picking winners' with the associated traps, while the other approach reminds us of a risky policy of 'backing losers'.

Although a public policy of 'facilitating clusters' may sound preferable and more desirable, we have argued that government still faces a knowledge problem about market processes. Therefore, the best motto for officials in charge for cluster policy 
is perhaps: "If you can't help, please do not harm". Indeed, examples of successful clustering reveal how little government can contribute to a cluster's performance. In fact, we only see a potential role for public authorities ex-post: they may brand the success of clusters after they have have emerged spontaneously in the market. In carrying out this 'cluster marketing' it is important to take into account and promote the particularities and realities of an area. After all, competition is not about copying, but about making a difference. Obviously, this is something different than trying to build the next 'Silicon Somewhere'. If governments want to have a policy aimed at clustering, they must apply a 'do-not-harm' approach. This does not leave much policy choice; in fact, facilitation and tax reduction (along with simplification of the regulatory burden for start-ups) may suffice. Therefore, governments that are inspired by the cluster concept should be modest and start from 'Regional Realism' rather than to try to build the next Silicon Valley.

Open Access This article is distributed under the terms of the Creative Commons Attribution Noncommercial License which permits any noncommercial use, distribution, and reproduction in any medium, provided the original author(s) and source are credited.

\section{References}

Bouwman, H., \& Hulsink, W. (2000). Silicon Valley in de Polder: ICT-clusters in de Lage Landen. Utrecht: Lemma.

Buss, T. F. (1999). The case against targeted industry strategies. Economic Development Quarterly, 13, 339-356.

Castells, M., \& Hall, P. (1994). Technopoles of the world: The making of twenty-first-century industrial complexes. London: Routledge.

Chang, H. J. (1994). The political economy of industrial policy. London: St. Martin's.

Clarke, R. (2001). The New Economy beyond the hype: The OECD Growth Project. Paris: OECD.

Cooke, P. (2002). Knowledge economies: Clusters, learning and cooperative advantage. London: Routledge.

Cowling, K., Oughton, C., \& Sugden, R. (1999). A reorientation of industrial policy: Horizontal policies and targeting. In K. Cowling (Ed.) Industrial policy in Europe: Theoretical perspectives and practical proposals. London: Routledge.

Desrochers, P. (2000). Geographical proximity and the transmission of tacit knowledge. Review of Austrian Economics, 14, 63-83.

Desrochers, P. (2001). Local diversity, human creativity and technological innovation. Growth and Change, 32, 369-394.

Drucker, P. (1985). Innovation and entrepreneurship. London: William Heinemann.

Dunn, W. N. (2003). Public policy analysis: An introduction (3rd ed.). New York: Prentice Hall.

Fingleton, E. (1999). In praise of hard industries. Boston, MA: Houghton-Mifflin.

Fuchs, G., \& Shapira, P. (2005). Rethinking regional innovation and change: Path dependency or regional breakthrough?. New York: Springer.

Griliches, Z. (1990). Patent statistics as economic indicators. Journal of Economic Literature, 28, 1661-1707. Hasssink, R. (1997). What distinguishes 'good' from 'bad' industrial agglomerations? Erdkunde, 51, 2-11.

Hayek, F. (1948). Individualism and economic order. Chicago: University of Chicago Press.

Hayter, R. (1997). The dynamics of industrial location. Chichester: Wiley.

Hospers, G. J. (2004a). Restructuring Europe's Rustbelt: structural change in the German Ruhrgebiet. Intereconomics: Review of European Economic Policy, 39, 147-156.

Hospers, G. J. (2004b). Regional economic change in Europe: A neo-Schumpeterian vision. Münster/ London: LIT. 
Howitt, P. (1996). The implications of knowledge-based growth for micro-economic policies. Calgary: The University of Calgary Press.

Jacobs, J. (1992). Systems of survival: A dialogue on the moral foundations of commerce and politics. New York: Vintage.

Josephson, P. (1997). New Atlantis revisited: Akademgorodok, the Siberian City of Science. Princeton: Princeton University Press.

Kirzner, I. M. (1979). The perils of regulation: a market-process approach. Reprinted in I. M. Kirzner 1985. Discovery and the capitalist process. Chicago: University of Chicago Press.

Kotler, P., Haider, D., \& Rein, I. (1993). Marketing places. New York: The Free.

Lux, T. (1995). Herd behaviour, bubbles and crashes. The Economic Journal, 105, 881-896.

MacDonald, S. (1992). Formal collaboration and informal information flow. International Journal of Technology Management, 7, 49-60.

Marshall, A. (1890 [1947]). Principles of economics. London: MacMillan.

Martin, S. (2001). Industrial organization: A European perspective. Oxford: Oxford University Press.

Martin, R., \& Sunley, P. (2003). Deconstructing clusters: Chaotic concept or policy panacea? Journal of Economic Geography, 3, 5-35.

McDonald, F., \& Dearden, S. (2005). European economic integration (5th ed.). Essex: Pearson Education.

Miller, R., \& Côté, M. (1985). Growing the next Silicon Valley. Harvard Business Review, 114-123, July/ August.

Norton, R. (1999). Cluster theories: Spatial externalities. In R. W. Jackson (Ed.) The web book of regional science. West Virginia University: Regional Research Institute.

O'mara, M. (2004). Cities of knowledge: Cold war science and the search for the next Silicon Valley. Princeton: Princeton University Press.

Porter, M. (2000a). Location, competition, and economic development: Local clusters in a global economy. Economic Development Quarterly, 14, 15-34.

Porter, M. (2000b). Location, clusters and company strategy. In G. L. Clark, M. S. Gertler, \& M. F. Feldman (Eds.) The Oxford handbook of economic geography. New York: Oxford University Press.

Puga, D. (2002). European regional policy in light of new location theories. Journal of Economic Geography, 2, 372-406.

Rainisto, S. (2003). Success factors of place marketing: A study of place marketing practices in Northen Europe and the United States. Helsinki: Helsinki University.

Reinert, E. S. (1995). Competitiveness and its predecessors: A 500-year cross-national perspective. Structural Change and Economic Dynamics, 6, 23-42.

Rosenfeld, S. (2001). Backing into clusters: Retrofitting public policies. Paper presented at the Integration Pressures: Lessons from Around the World-John F. Kennedy School Symposium at Harvard University, March 29-30.

Salacuse, J. W. (1994). The art of advice. New York: Crown.

Sautet, F. (2002a). Economic transformation, the pretence of knowledge and the process of entrepreneurial competition. New Zealand Treasury Discussion Paper.

Sautet, F. (2002b). Kirznerian economics: Some policy implications and issues. Journal des Economistes et des Etudes Humaines, 1, 131-151.

Saxenian, A. L. (1994). Regional advantage: Culture and competition in Silicon Valley and Route 128. Cambridge, MA: Harvard University Press.

Schmookler, J. (1966). Invention and growth. Cambridge: Harvard University Press.

Schumpeter, J. A. (1912). Die Theorie der Wirtschaftlichen Entwicklung. Leipzig: Duncker and Humblot.

Schumpeter, J. A. (1950). American institutions and economic progress. Reprinted in Swedberg, R. 1991. Joseph A. Schumpeter: The economics and sociology of capitalism. Princeton: Princeton University Press.

Smith, A. (1776 [1976]). An inquiry into the nature and causes of the wealth of nations. Oxford: Clarendon Press, (textual editor W.B. Todd).

Storper, M., \& Scott, A. J. (1995). The wealth of regions. Futures, 27, 505-526.

Stuart, W. L., \& Kargon, R. (1996). Selling Silicon Valley: Frederick Terman's model for regional advantage. Business History Review, 70, 435-472.

Tinbergen, J. (1952). On the theory of economic policy. Amsterdam: North-Holland.

Tödtling, F., \& Trippl, M. (2004). Like Phoenix from the ashes? The renewal of clusters in old industrial areas. Urban Studies, 41, 1175-1195.

Witt, U. (1993). Evolutionary economics. Cheltenham: Edward Elgar.

Wolf, C. (1990). Markets or governments: Choosing between imperfect alternatives. Cambridge, MA: The MIT Press. 